\title{
Fabrication and characterization of epoxy modified with $0.5 \%$ MWCNTs
}

\author{
Original \\ Article \\ Amal A.M. Badawy and Eman U.A. Khashaba \\ Department of Materials Engineering, Faculty of Engineering, Zagazig University, \\ Zagazig, Egypt
}

\section{Keywords:}

Drop weight impact test, iosipescu shear test, multi-walled carbon nanotubes, tensile, ultrasonic dispersion.

\section{Corresponding Author:}

Eiman U. Khashaba, Department of Materials Engineering, Faculty of Engineering, Zagazig University, Zagazig, Egypt, Tel: 00201140139757

Email:e_khashaba@hotmail.com.

\section{Abstract}

In the present work, tensile, shear and impact properties of epoxy modified with multi-walled carbon nanotubes (MWCNTs) are measured experimentally in accordance with ASTM standards.The MWCNTs were dispersed into the epoxy resin using ultrasonic processor. To avoid damaging the nanotubes, the sonication process was performed at low-amplitude $(225 \mathrm{~W})$ in a short duration of $30 \mathrm{~min}$. The mixture was evacuated to remove air bubbles before further mixing with hardener. Results from the experimental study showed that incorporation of the MWCNTs into the epoxy resin improves the tensile strength and modulus of the MWCNT-nanocomposite by $11 \%$ and $68.7 \%$, respectively, compared with those of the neat epoxy. The shear strength and inplane shear modulus of the MWCNT-nanocomposite were improved by $22.2 \%$ and $29 \%$, respectively. The drop weight impact performance of the MWCNT-nanocomposite showed an improvement in the maximum contact force and the absorbed energy of the MWCNT-nanocomposite by $9.5 \%$ and $11.4 \%$, respectively.

\section{INTRODUCTION}

One of the important limiting factors for the use of multi-walled carbon nanotubes (MWCNTs) in modifying the epoxy resin is their agglomeration and poor distribution/ dispersion especially at high concentrations. The van der Waals attractive interactions owing to high aspect ratio of MWCNTs leads to agglomeration in the form of bundles or ropes ${ }^{[1]}$ with highly entangled network structures, which are very difficult to disperse. Hence, in the present study, the sonication parameters were carefully selected to minimize the agglomeration of MWCNTs in the epoxy resin. Moderate loading percentage of MWCNTs can result in good dispersion as well as lower agglomeration. Accordingly, based on the extensive literature survey, a 0.5 $\mathrm{wt} \%$ MWCNTs was selected that showed improvements in the mechanical properties for different epoxy systems by many researchers ${ }^{[2-11]}$.

Sonication parameters can play a vital role in the dispersion of nanomaterials in polymer resin. The most important parameters include viscosity of the polymer resin, type of nanomaterials, temperature control, cooling medium (air, water, water/ice), beaker material and dimensions, immersion depth of the sonicator probe, sonicator probe diameter, sonication mode (pulse or continuous) sonication power and amplitude, sonication time and sonication energy densities $(\mathrm{W} \cdot \mathrm{s} / \mathrm{ml})^{[7]}$. Sonication of carbon nanotubes (CNTs) can lead to defects on the walls and the ends of the CNTs and even cutting the nanotubes ${ }^{[12-14]}$. To avoid damaging of carbon nanotubes (CNTs), the sonication time should be in the range of 20 to $30 \mathrm{~min}$ as recommended by $\mathrm{Hu}$ et al. ${ }^{[12]}$. Therefore, in this study the sonication process was performed at lowamplitude $(225 \mathrm{~W})$ in a short duration of $30 \mathrm{~min}$.

Jen and Wang ${ }^{[2]}$ reported that the static strength was slightly decreased due to agglomeration of the CNTs when the CNT exceeds $0.5 \mathrm{wt} \%$. Mactabi et al.$^{[3]}$ reported that the $0.5 \mathrm{wt} \%$ MWCNTs has the highest improvement in the average shear strength of the single lap joint compared with neat and $1.0 \mathrm{wt} \%$ MWCNTs. Khashaba et al. ${ }^{[7]}$ found that the nanocomposite with $0.5 \mathrm{wt} \%$ of MWCNTs has the maximum tensile properties compared with that have weight percentages of $0.25 \mathrm{wt} \%, 0.75 \mathrm{wt} \%$ and $1.00 \mathrm{wt} \%$ MWCNTs. The good dispersion of $0.5 \mathrm{wt} \%$ MWCNTs in epoxy adhesive was result in high improvements in the mechanical properties of scarf adhesive joint in carbon fiber composites, as reported by Khashaba et al. ${ }^{[8,11]}$.

The well-dispersed nanofillers in epoxy resin can act as a physical cross-links for the molecular chains ${ }^{[15,16]}$ that leads to an improvement in the interfacial properties. For the CNT-nanocomposites, it is expected that part of the applied load can be transferred from the weak matrix to the nanofillers with higher mechanical properties (predicted tensile strengths of $100 \mathrm{GPa}$ and elastic modulus of up to $1 \mathrm{TPa}^{[17]}$ ), and thus improving the mechanical properties 
of the nanocomposites. The very low volume (or weight) fractions of the CNTs (for reducing the agglomeration effects) as well as their short-length are the limiting factors for the achievable structural components with high mechanical properties.

The increased stiffness of the modified epoxy with MWCNTs has different effects on the other mechanical properties such as absorbed energy. Therefore, any selection of material characteristics for optimal impact energy should consider the other mechanical properties. Accordingly, the main objective in the present study is to investigate the effects of MWCNTs infusion into epoxy resin on the tensile, shear and impact properties, grouped in one article. The MWCNTs was dispersed using sonication technique. The sonication parameters were carefully selected to minimize the agglomeration as well as the damage of MWCNTs. A series of ASTM tests was performed to characterize the tensile, in-plane shear and impact properties of the fabricated MWCNTnanocomposites and the results were compared with those of the neat epoxy.

\section{Experimental Work}

\subsection{Materials}

The used epoxy consists of two parts, which are: epoxy part-A (Araldite PY 1092-1) and epoxy part-B (Hardener HY 1092). The weight mixing ratio is 100:45 respectively. The epoxy system was developed by Huntsman Advanced Materials, Americas for manufacturing FRP composites for structural engineering. The MWCNTswere manufactured by Timesnano, Chengdu Organic Chemicals using Chemical Vapor Deposition technique. The physical properties of the epoxy resin as well as MWCNTs are shown in Table 1.

Table 1: Typical properties of the constituent materials of the MWCNT-nanocomposite

\begin{tabular}{|c|c|}
\hline Materials & Properties \\
\hline Epoxy resin & $\begin{array}{l}\text { - Viscosity of PY } 1092-1 / \mathrm{HY} 1092 \text { epoxy system is } 300 \mathrm{mPa} \text {. } \\
\text { sat } 25^{\circ} \mathrm{C} \\
\text { - Density of epoxy system is } 1.1034 \mathrm{~g} / \mathrm{cm}^{3} \text {. }\end{array}$ \\
\hline Non-functionalized Multi-Walled Carbon Nanotubes (MWCNTs) & $\begin{array}{l}\text { - Length } \approx 30 \mu \mathrm{m} \\
\text { - Inner diameter } 2-5 \mathrm{~nm} \\
\text { - Outer diameter }<8 \mathrm{~nm} \\
\text { - Density }=2.1 \mathrm{~g} / \mathrm{cm}^{3} \\
\text { - Purity }>95 \mathrm{wt} \%\end{array}$ \\
\hline
\end{tabular}

\subsection{Preparation of Neat Epoxy Panels}

Glass mold with dimensions of $350 \mathrm{~mm} \times 350 \mathrm{~mm}$ was used to fabricate the neat epoxy panels. Four glass strips with dimensions of $6 \mathrm{~mm}$ thickness, $10 \mathrm{~mm}$ width and $340 \mathrm{~mm}$ length were bonded by silicon rubber on the four edges of the glass plate to prevent sealing the epoxy from the mold. The glass mold was treated by liquid wax to prevent sticking the epoxy panel with glass mold. The wax was dry up within 4-5 minutes. To obtain epoxy panel with constant thickness, the mold was adjusted horizontally using three leveling water balances as shown in Fig. 1a.

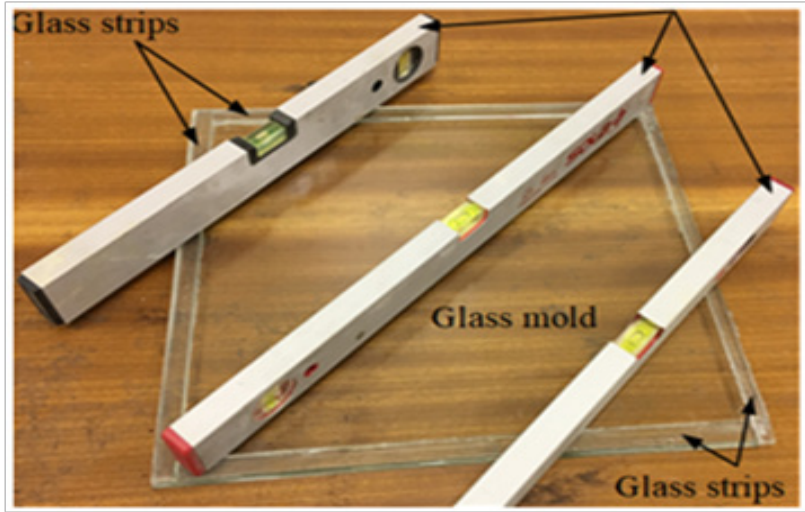

Epoxy part B was added gradually to epoxy part A and manually stirred for $10 \mathrm{~min}^{[18]}$. The epoxy was poured into waxed glass mold box, which positioned in a horizontal plane using three leveling water balances as shown in Fig. 1a. The high surface area of the mold and low viscosity of the epoxy allow trapped air voids to escape from mold. Then, the mold was cured at room temperature for 21 days. The four glass strips that were bonded on the mold edges are removed by shearing the silicon layer by sharp cutter. Now, it is easy to remove the epoxy panel from the glass mold as shown in Fig. 1b. The thickness of the fabricated neat epoxy panels was $\approx 4.25 \mathrm{~mm}$.

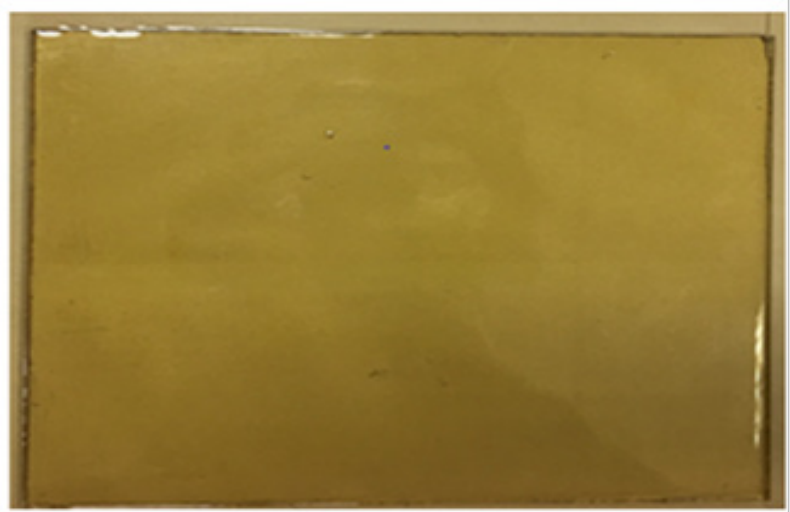

Fig. 1: Fabrication of neat epoxy panel: (a) Glass mold treated by liquid wax, and (b) The fabricated panel 
2.3. Fabrication of MWCNT-Nanocomposite

2.3.1. Determination the mass of MWCNTs and epoxy

Because MWCNTs have large aspect ratio (length/ diameter), they tend to aggregate and form bundles or ropes, usually with highly entangled network structure, which significantly limits their dispersion in the epoxy resin. Agglomerations of MWCNTs reduce the interfacial area in the nanocomposites, and hence reduce the opportunity to take the advantage of the unique properties of the MWCNTs ${ }^{[19]}$. Based on the extensive literature survey, a $0.5 \mathrm{wt} \%$ MWCNTs was selected, which showed improvements in the mechanical properties for different epoxy systems by many researchers ${ }^{[2-11]}$. The mass of the MWCNTs was estimated based on the total mass of PY 1092-1/HY 1092 epoxy system using digital balance with sensitivity of $0.0001 \mathrm{~g}$.

\subsubsection{Manual stirring}

The $0.5 \mathrm{wt} \%$ MWCNTs $(2.76 \mathrm{~g})$ is mixed manually in $552 \mathrm{~g}\left(500 \mathrm{~cm}^{3}\right)$ epoxy part-A by adding them little by little during the manual stirring of the epoxy. The manual stirring of MWCNT/epoxy mixture is continued up to $5 \mathrm{~min}$ before the sonication process to avoid the agglomeration.

\subsubsection{Sonication of MWCNTs/Epoxy Mixture}

The MWCNTs were dispersed in epoxy part-A (PY 1092-1) using Ultrasonic Processor (model ColeParmer $750 \mathrm{~W}$ ). The dispersion of MWCNTs is more difficult in a viscous medium, due to the sharp increase of the polymer viscosity with increasing the nanofiller loading percentage $^{[20]}$. Accordingly, the following sonication parameters were carefully selected from the literature review:

- The MWCNTs-epoxy mixture is powered into aluminum beaker of $80 \mathrm{~mm}$ diameter. The generated heat during the sonication process was dissipated through the high thermal conductivities aluminum beaker, which subjected to watercooling bath. The small diameter of the aluminum beaker maximizes the contact surface area of the mixture with the beaker wall as well as with sonicator probe, which increases the dissipation of the heat and improves the dispersion of the MWCNTs in the epoxy resin.

- The Cole-Parmer Ultrasonic Processor was supplied with two sonicator probe of $12.5 \mathrm{~mm}$ and $25 \mathrm{~mm}$ diameter. The sonicator probe with larger diameter was selected to provide energy released over a greater area ${ }^{[20,21]}$. It was positioned at the center of the beaker and immersed to a depth of $50 \mathrm{~mm}$ (keeping a gap of $20 \mathrm{~mm}$ with the beaker bottom). Large probe immersion depth increases the mixture surface area that was exposed to the acoustic waves and thus improves the dispersion of the MWCNTs in the epoxy resin.

- The sonication temperature of the mixture was kept less than or equal to $50^{\circ} \mathrm{C}$ via the temperature probe, which is clamped at a distance of $1 \mathrm{~cm}$ away from the sonicator probe. The sonication process stops and restarts automatically for temperatures higher and lower than $50^{\circ} \mathrm{C}$, respectively.

- The sonication amplitude (input power into the mixture) is an important parameter in dispersion of MWCNTs into the epoxy resin. The increased viscosity of the epoxy owing to infusion of MWCNTs can dampen the cavitation process. The literature on the sonication parameters of CNTs showed that the sonication process can damage nanotubes by causing defects on their ends, walls and even cutting the tubes as reported by $\mathrm{Hu}$ et al. ${ }^{[12]}$. They recommended that the sonication time should be much shorter. Therefore, to avoid damaging of MWCNTs, a $30 \%$ sonication amplitude $(=30 \times 750 / 100=225 \mathrm{~W})$ was implemented for $30 \mathrm{~min}$ to disperse them into the epoxy resin. Thus, the estimated energy densities during the sonication of MWCNTs mixture was $810 \mathrm{~W} \bullet \mathrm{s} / \mathrm{ml}$.

- The sonication of MWCNT/epoxy mixture was performed in pulsed mode with $15 \mathrm{~s}$ on and $30 \mathrm{~s}$ off to delay the rate of temperature increase and thus provide a better temperature control compared with continuous mode process.

\subsubsection{Removing Bubbles from the MWCNT-Epoxy} Mixture using Drying Vacuum Oven

The developed cavitation bubbles during the sonication processes are cyclically growing until they attain a critical diameter that induces implosive collapse ${ }^{[20,22]}$ accompanied with splitting up the agglomerated nanofillers. The shock waves from the implosive collapse of the bubbles. The micro-streaming generated by cavitation oscillations leads to dispersion effects. Thus, the sonication process greatly contributes to the removal of air bubbles for the mixture.

To complete removing of the trapped bubbles, the sonicated mixture is placed in vacuum drying oven Model DZF-6050 at $133 \mathrm{~Pa}$. The increased viscosity of nanophased epoxy (especially with high nanofiller loading percentage) prevents the bubbles from escape even under vacuum conditions. Therefore, it is essential to apply heating to the nanophased epoxy during evacuation processes. For this purpose, vacuum drying oven was used as following:

- The nanophased epoxy $\left(500 \mathrm{~cm}^{3}\right)$ was kept in a wide glass beaker with $5000 \mathrm{~cm}^{3}$. Therefore, the height of the epoxy in this baker is less than $1 / 10$ its total height (of $500 \mathrm{~cm}^{3}$ beaker). This will maximize the mixture surface area, and accordingly allow the bubbles to escape freely.

- The wide container is then placed into an oven that has been pre-heated to $40^{\circ} \mathrm{C}$ for approximately thirty minutes ${ }^{[23]}$.

- The bubbles can be easily observed visually accumulated on the surface of the nanophased epoxy. Most of the bubbles are not collapsed owing to their high surface tension.

Applying vacuum of $133 \mathrm{~Pa}$ for $30 \mathrm{~min}$ can easily remove all the observed bubbles on the surface and that inside the mixture.

\subsubsection{Mixing the MWCNT/epoxy-A with Epoxy} Part-B and pouring into waxed mold

Before adding epoxy part-B to MWCNT, epoxy-Ait 
should be cooled at the room temperature. This because raising the evacuation temperature of epoxy to $40^{\circ} \mathrm{C}$ can act as a catalyst and speed up the cure. The mixture (MWCNT/ epoxy-A) is manually stirred using wooden strip and the hardener (epoxy part-B) is added drop by drop, while the stirring is continued up to about $5 \mathrm{~min}^{[18]}$. The MWCNTnanocomposite panels with thickness of $\approx 4.6 \mathrm{~mm}$ are prepared by pouring the nanophased epoxy into glass mold $(350 \mathrm{~mm} \times 350 \mathrm{~mm}$ ) that treated by liquid wax.

\subsubsection{Cutting the test specimens}

The test specimens were cut according to the ASTMs dimensions using $\mathrm{CNC}$ abrasive water jet machine. The main advantage of the abrasive water jet cutting process is the eliminating of generated temperature that accompanied with conventional cutting operations. The generated temperature can soften and/or burn the matrix that resolidified after cooling. Re-solidifying of the cut zone in the polymer specimens is always accompanied with high stress concentration, which can leads to premature failure under mechanical loads of the testing machines.

\subsection{Mechanical testing}

\subsubsection{Tension tests}

The tensile properties of the NE and the MWCNTnanocomposite were determined according to ASTM D 638. The test specimens were cut to the dimensions shown in Fig. 2, ASTM D 638. Images of the machined NE and MWCNT-nanocomposite tensile specimens were illustrated in Fig. 3. The tensile tests were performed on servohydraulic universal testing machine (Instron 8872, $10 \mathrm{kN}$ ) at ambient laboratory environment. The capacity of the selected testing machine is very suitable for testing neat epoxy as well as MWCNT-nanocomposite. The longitudinal strain was recorded during the tensile test using Extensometer (Instron 2620-601) with gauge length of $50 \mathrm{~mm}$, as shown in Fig. 4. At least, four test specimens were tested, for each material type, at constant cross-head speed of $1.0 \mathrm{~mm} / \mathrm{min}$. The ultimate tensile strength $(\sigma)$ was calculated by dividing the ultimate tensile load $\mathrm{P}_{\text {ult }}$ by the cross-section area $(A)$; while, true modulus $\left(E_{T}\right)$ was estimated from the slope of the initial linear region of the stress-strain curve.

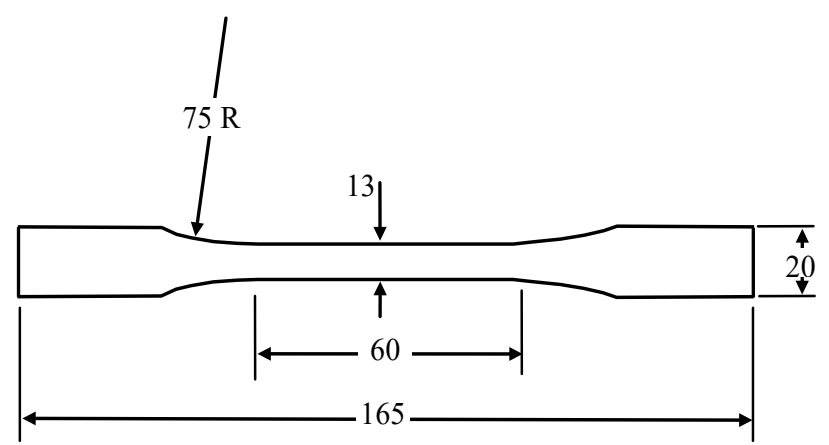

Fig. 2: Dimensions of tensile specimens, ASTM D 638

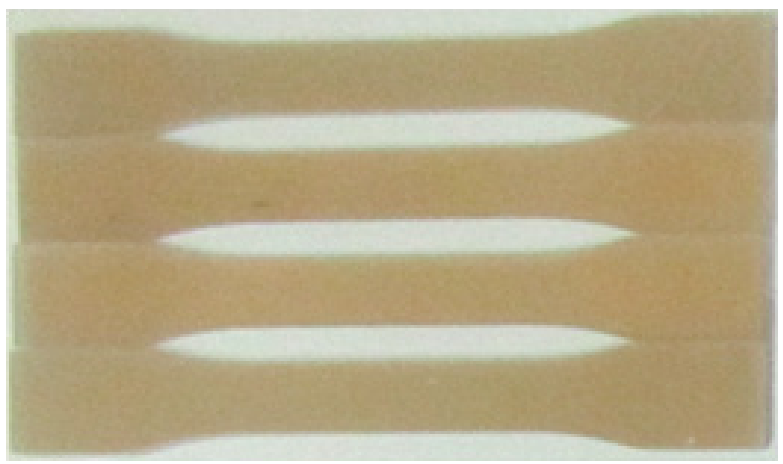

(a) Neat epoxy (NE)

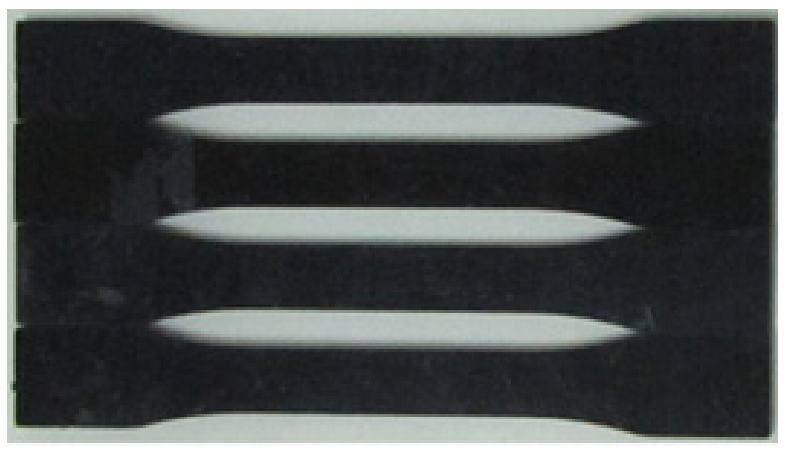

(b) MWCNT-nanocomposite

Fig. 3: Tensile specimens: (a) Neat epoxy, and (b) MWCNTnanocomposite

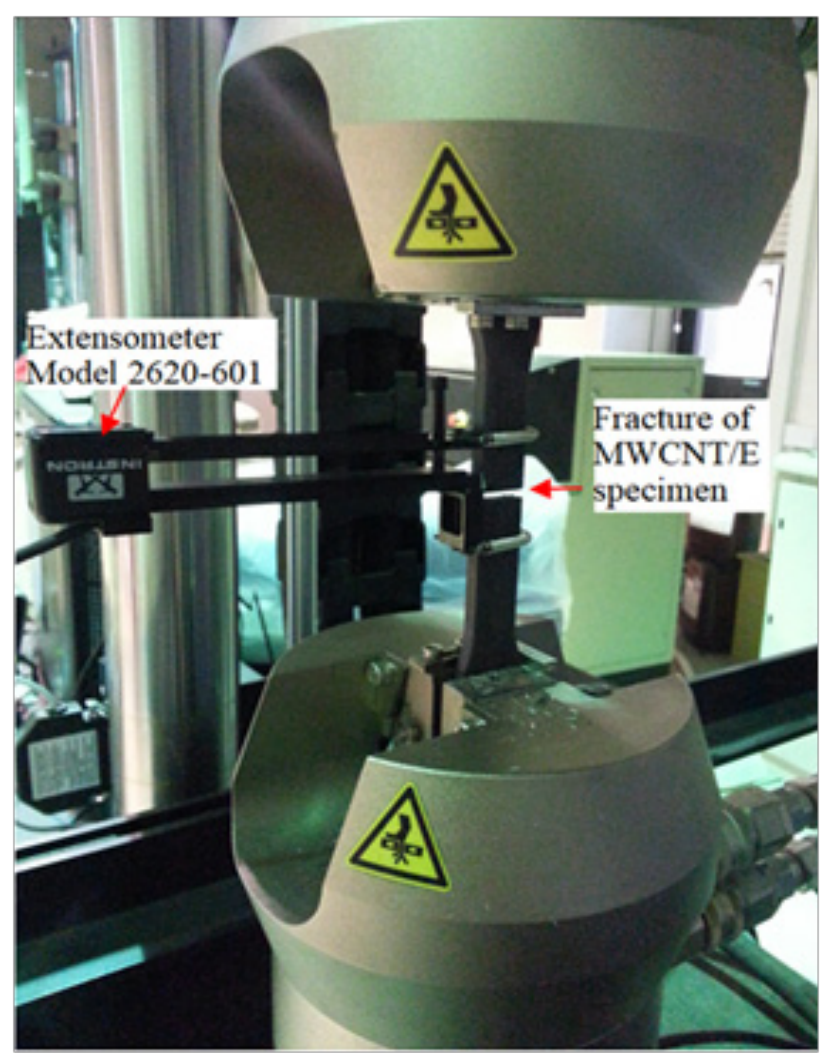

Fig. 4: Experimental setup for tension tests 


\subsubsection{In-Plane shear tests}

In-plane shear tests were carried out on neat epoxy and MWCNT-nanocomposite using double V-notch specimens, and Iosipescu shear test fixture according to ASTM D5379 as shown in Figs. 5 and 6. The dimensions of the test specimen are indicated in Fig. 5a. At least five double V-notches specimens were cut for both NE and MWCNT-nanocomposite. For each material type, four

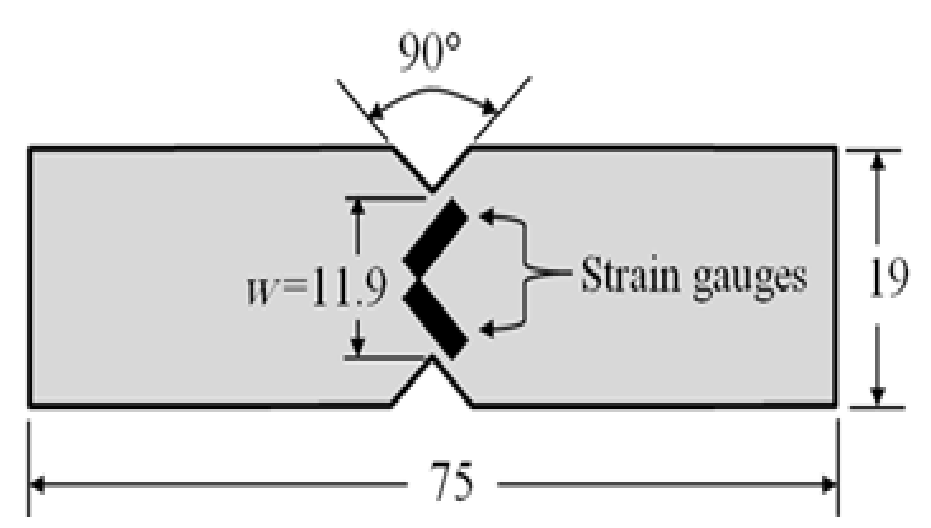

(a) specimens were instrumented with $\pm 45^{\circ}$ strain gauges to measure the shear strain $\left(\gamma_{\mathrm{xy}}\right)$, and thus shear modulus $\left(G_{x y}\right)$, Fig. 5b. The strains were acquired via 4-channels Data Acquisition (Model $9237 \mathrm{NI}$ ), which were connected to a computer. The test specimens were loaded in shear via the Iosipescu shear test fixture using a universal testing machine (model Instron Model 8872) according to ASTM D5379, see Fig. 7.

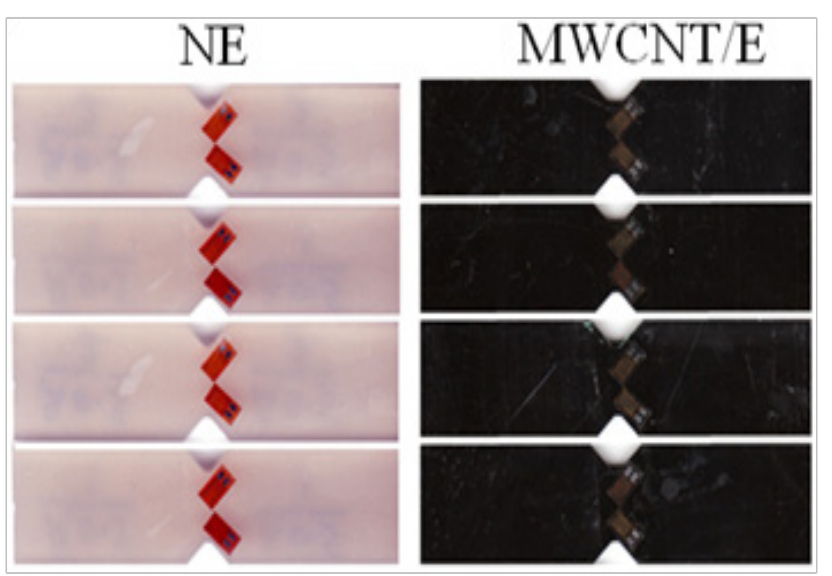

(b)

Fig. 5: Shear test specimens: (a) Dimensions, and (b) images of the double V-notches specimens

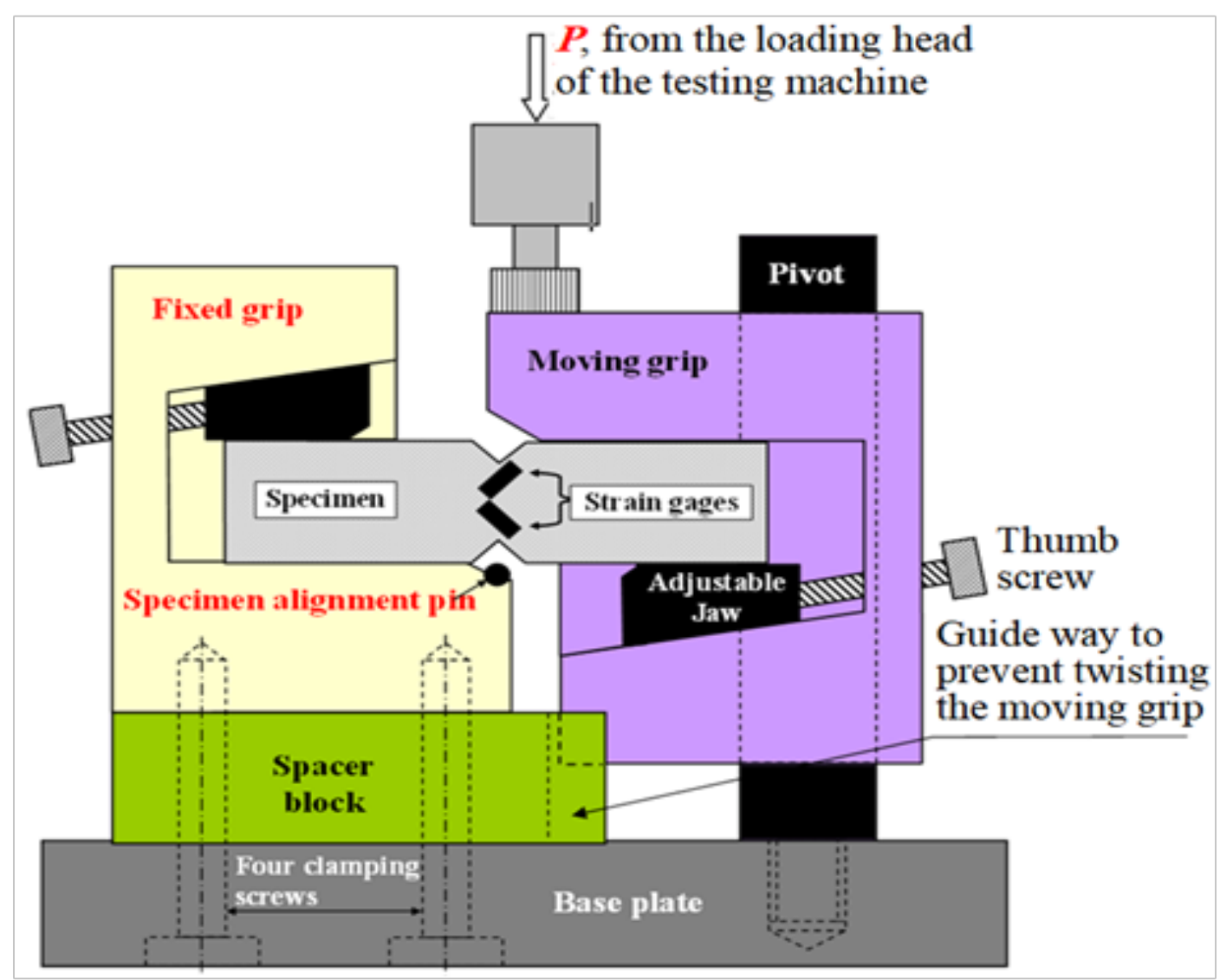

Fig. 6: Iosipescu shear tests fixture 


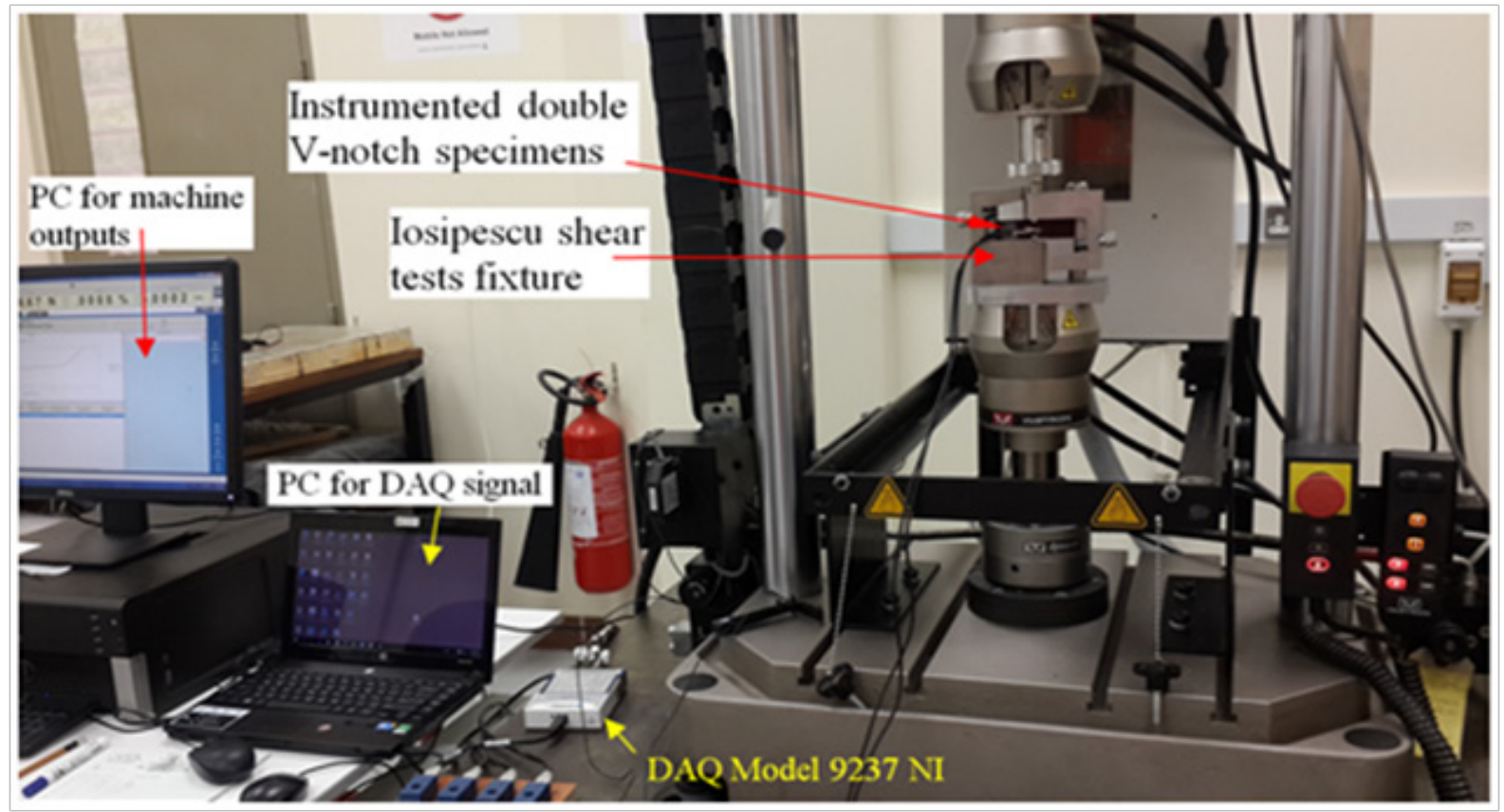

Fig. 7: Instron testing machine Model 8872 with in-plane shear test setup

The principle of the Iosipescu shear test is to apply a displacement, with a constant rate of $1 \mathrm{~mm} / \mathrm{min}$, on the double $\mathrm{V}$-notch specimen via the movable grip, which results in constant shear force and pure shear stress (zero bending moment $)^{[24,25]}$ at the central region of the specimen. The in-plane shear strength $\left(\gamma_{\mathrm{xy}}\right)$ was calculated from the following equation:

$$
\tau_{x y}=\frac{P}{A}
$$

where $P$ is the ultimate load, and $A$ is the cross-sectional area between the roots of the two V-notches.

The in-plane shear modulus $\left(\mathrm{G}_{\mathrm{xy}}\right)$ was estimated from the slope of the initial linear region of shear stress vs shear strain curves $\left(\Delta \tau_{x y} / \Delta \gamma_{x y}\right)$ as:

$$
G_{x y}=\frac{\Delta \tau_{x y}}{\Delta \gamma_{x y}}
$$

Where $\gamma_{\mathrm{xy}}$ the in-plane shear strain, which was estimatedas follows[25]:

$$
\gamma_{\mathrm{xy}}=\varepsilon_{-45}-\varepsilon_{+45}
$$

Where $\varepsilon_{-45}$ and $\varepsilon_{+45}$ are the measured strains of the $-45^{\circ}$ and $+45^{\circ}$ strain gauges, respectively.

\subsubsection{Impact Tests}

Drop mass impact tests were performed in accordance with ASTM D 7136 using instrumented falling weight impact tester (model CEAST 9340) as shown in Fig. 8a. Three specimens were cut for both NE and MWCNTnanocomposites to dimensions of $101.6 \times 152.4 \pm 0.1 \mathrm{~mm}$, ASTM D 7136. The specimen was fixed inside thermal conditioning chamber on a steel plate with rectangular window of $75 \times 125 \mathrm{~mm}$ using four clamps, Fig. 8b. All the impact tests were performed at impact energy of $20 \mathrm{~J}$ and total mass $\left(m_{T}\right)$ of $12.632 \mathrm{~kg}$, which equal the sum of tup holder mass of $2.5 \mathrm{~kg}$, tup mass of $0.632 \mathrm{~kg}$, and the additional mass of $9.5 \mathrm{~kg}$. From Eq. (4), the software of the testing machine estimates the impactor height $(\mathrm{H}=0.161$ $\mathrm{m})$ and the initial impact velocity $(v=1.779 \mathrm{~m} / \mathrm{s})$ using Eq. (5), with acceleration due to gravity of $9.81 \mathrm{~m} / \mathrm{S}^{2}$.

$$
H=\frac{E}{m_{T} g}
$$

$$
v=\sqrt{2 g H}
$$



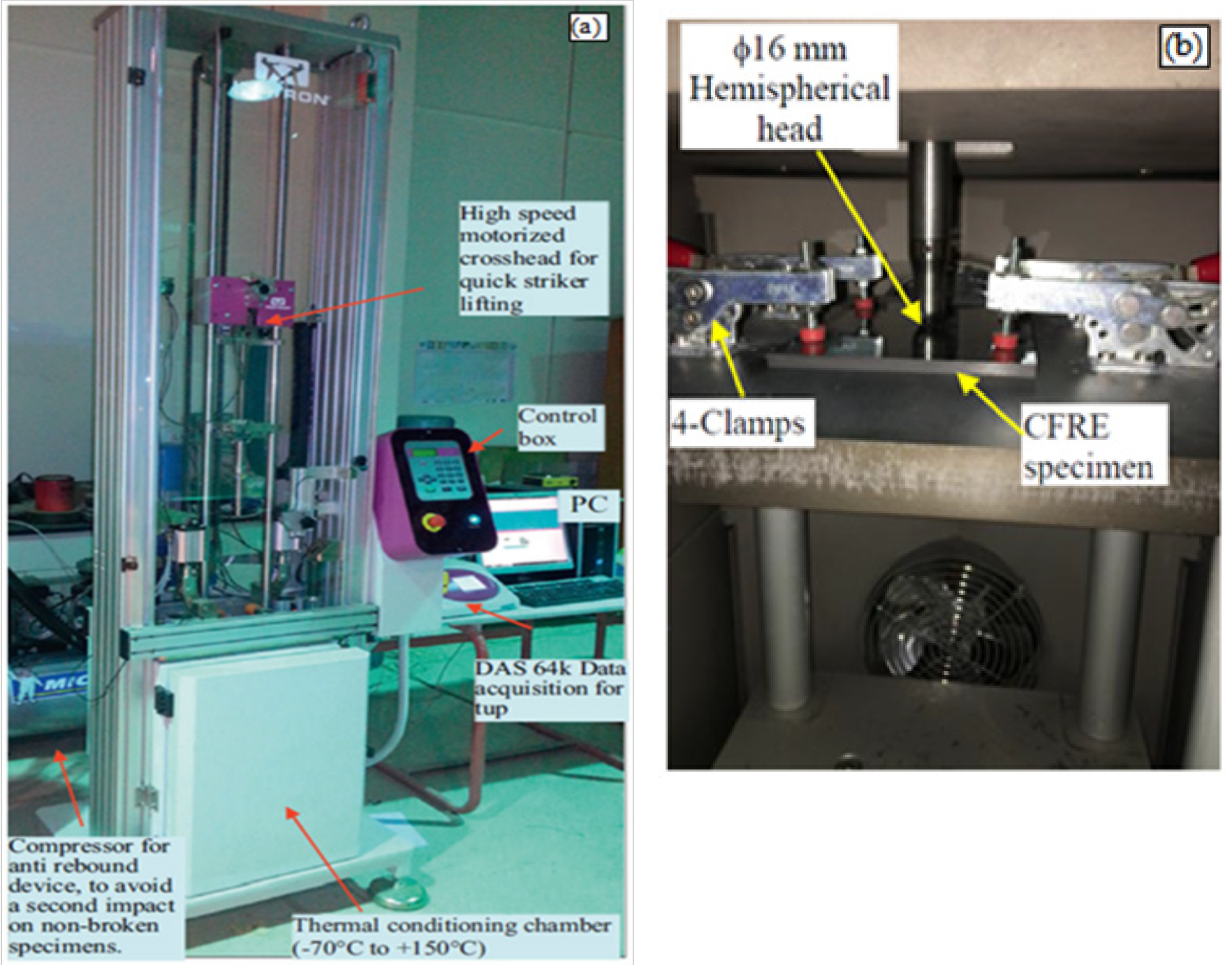

Fig. 8: Impact test machine (a) falling weight impact tester, and (b) thermal conditioning chamber showing specimen fixtures.

The results of the CEAST 9340 falling weight impact tester can be obtained directly on the PC monitor as well as saved in XLS sheet to establish the following relationships: force-time/displacement relationships, energy-time/ displacement relationships and peak points.

\section{Results and discussions}

\subsection{Tension Test Results}

Fig. $9 \mathrm{a}$ and $\mathrm{b}$ shows the tensile stress-strain curves of neat epoxy (NE) and MWCNT-nanocomposite, respectively. The stress-strain curves typically behave almost linearly, followed by nonlinear plastic behavior. The true Young's modulus of NE and MWCNTnanocomposite were estimated from the slope of the initial linear region of the stress-strain curves. Fig. 10 shows images of some fractured specimens, which indicates that the failure occurred in the gauge length typically, as specified by the ASTM D 638.

Figs. 11 and 12 show comparison between the average tensile strength and modulus of both NE and MWCNTnanocomposite, respectively. The results in Fig. 11 showed that the improvement percentage in the tensile strength of the MWCNT-nanocomposite is $11 \%$ compared with neat epoxy (NE). The results in Fig. 12 showed that the improvement percentage in the true tensile modulus of the MWCNT-nanocomposite is $68.7 \%$ compared with neat epoxy (NE). The well dispersed MWCNTs in epoxy resin act as physical cross-links for the epoxy molecular chains $^{[15,16]}$ that leads to an improvement in the interfacial bonding between them. Hence, the applied mechanical loads can be effectively transferred from the weak matrix to the high strength $(100 \mathrm{GPa})$ and high modulus $(1 \mathrm{TPa})$ $\mathrm{CNTS}^{[17]}$, which played an important role in improving the tensile properties (strength and modulus) of the nanocomposite. 


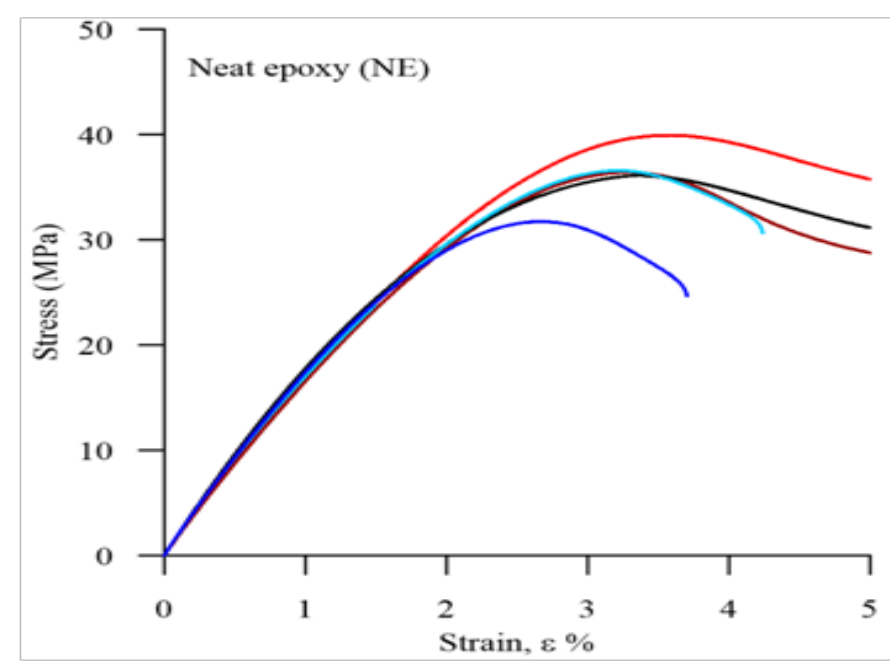

(a)

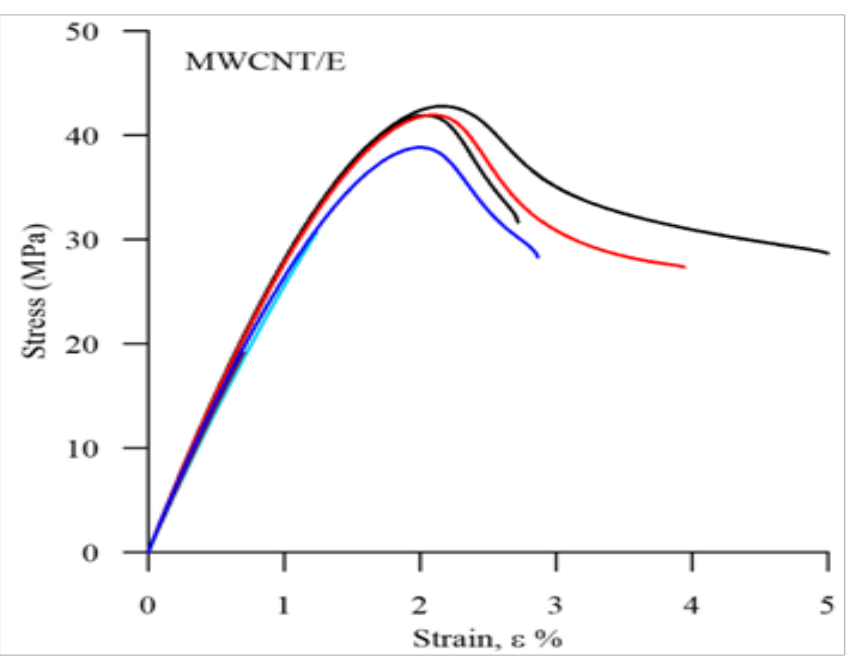

(b)

Fig. 9: Stress-strain curves of: (a) neat epoxy, and (b)MWCNT-nanocomposite.

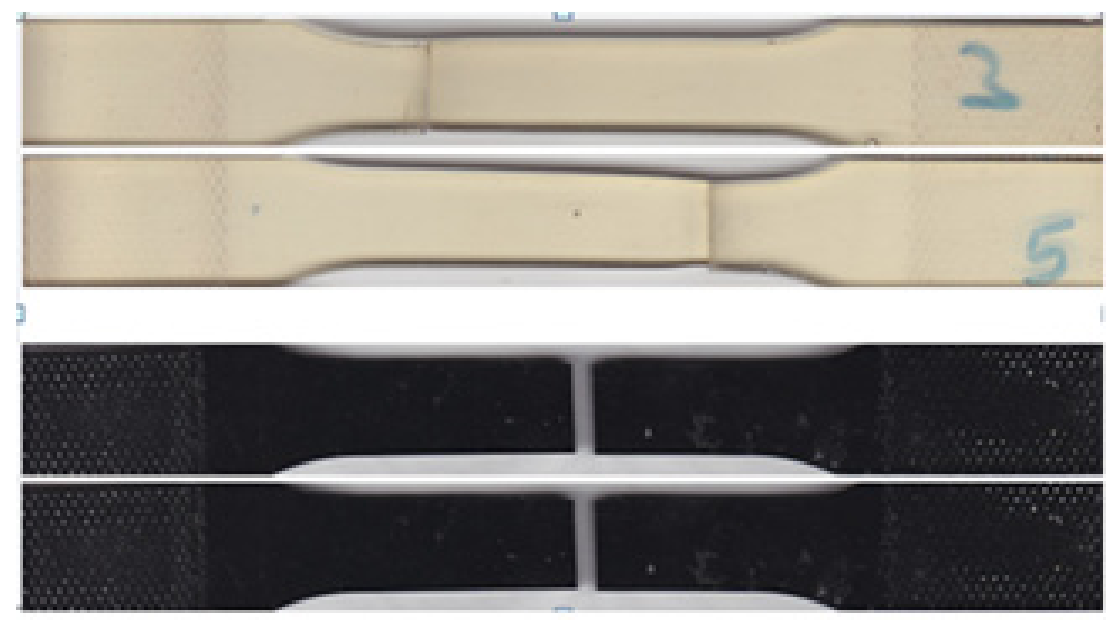

(a)

Fig. 10: The fractured specimens in tension test for: (a) NE, and (b) MWCNT-nanocomposite.

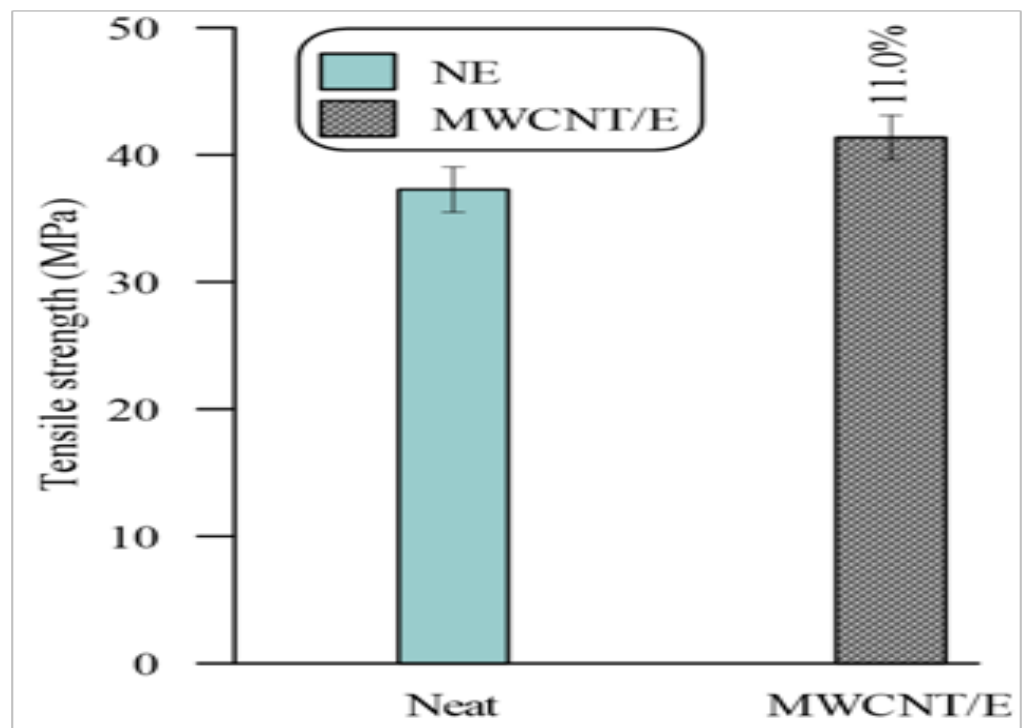

Fig. 11:Tensile strength of NE and MWCNT-nanocomposites and the improvement percentage. 


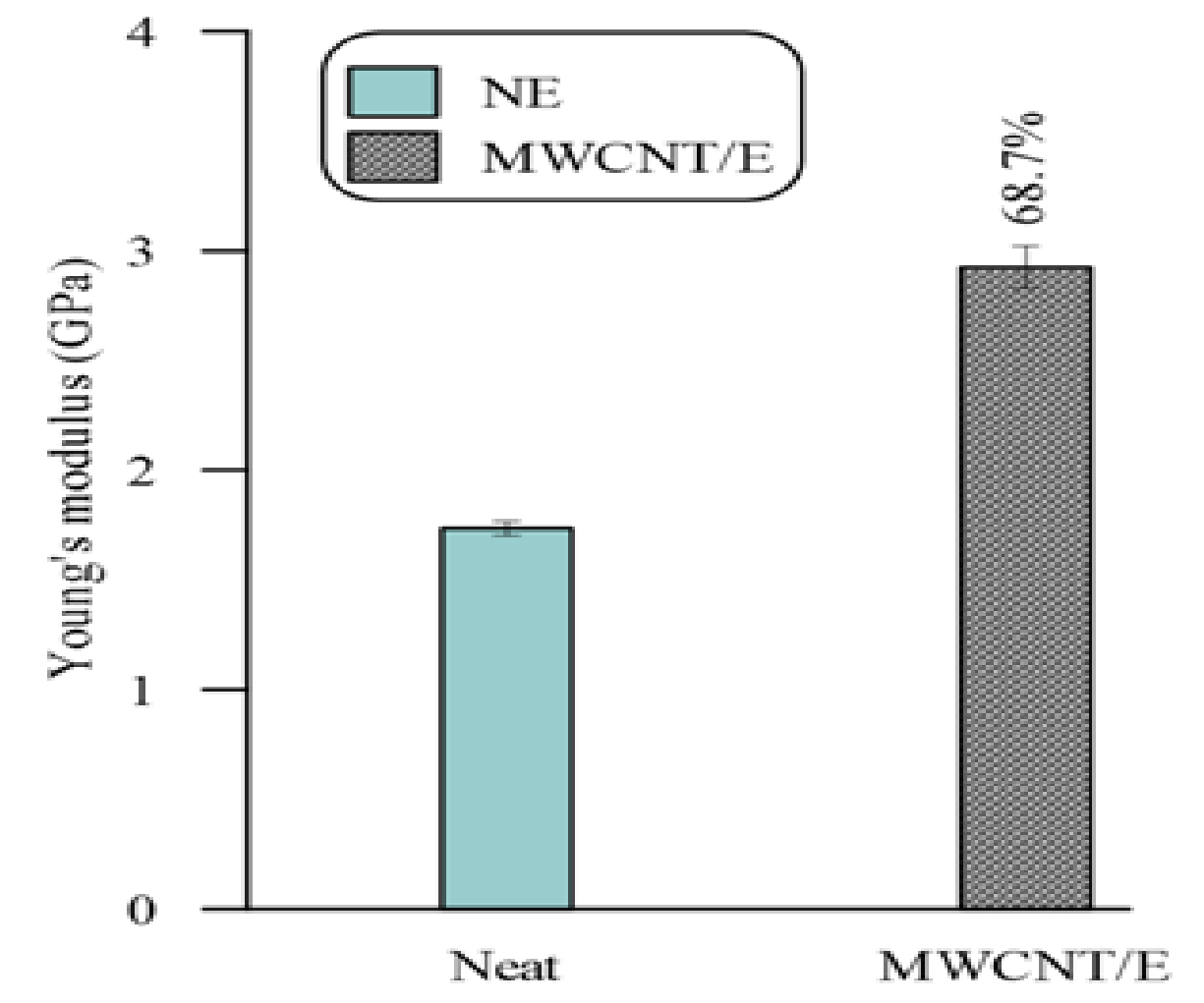

Fig. 12: Young's modulus of NE and MWCNT-nanocomposites and the improvement percentage.

\subsection{In-Plane Shear Test Results}

Shear load versus displacement relationships of neat epoxy and MWCNT-nanocomposite are illustrated in Fig. $13 \mathrm{a}$ and (b), respectively. The load-displacement curves in

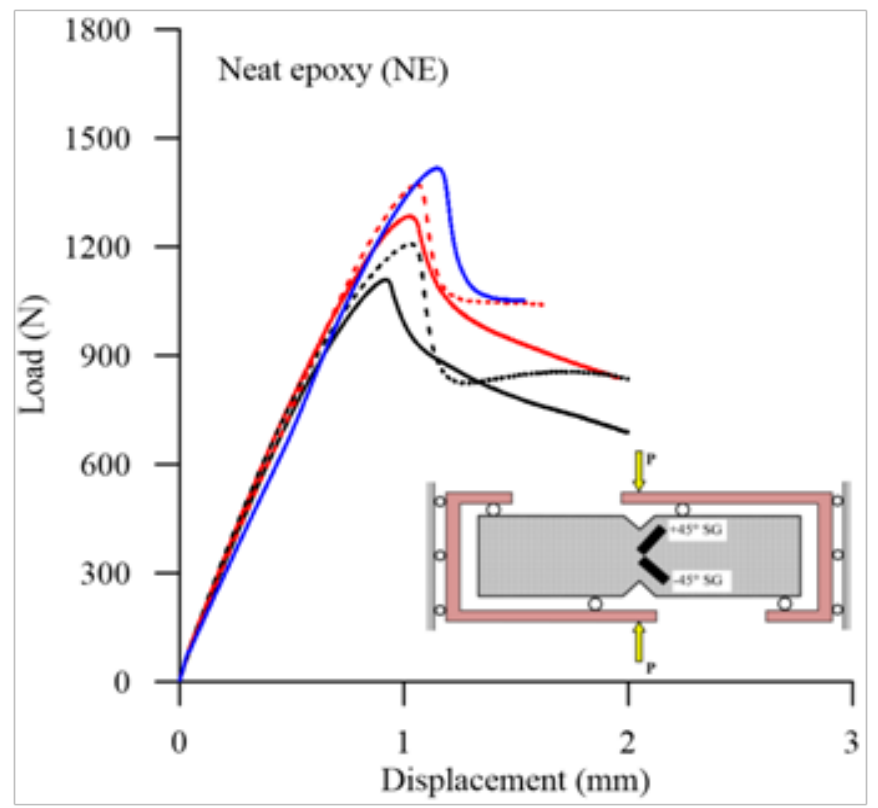

(a) these figures typically behave almost linearly, followed by nonlinear behavior and plastic deformation at the ultimate load. The load is then decreased due to crack from the tip of the V-notch toward the specimen center, as shown in Fig. 14.

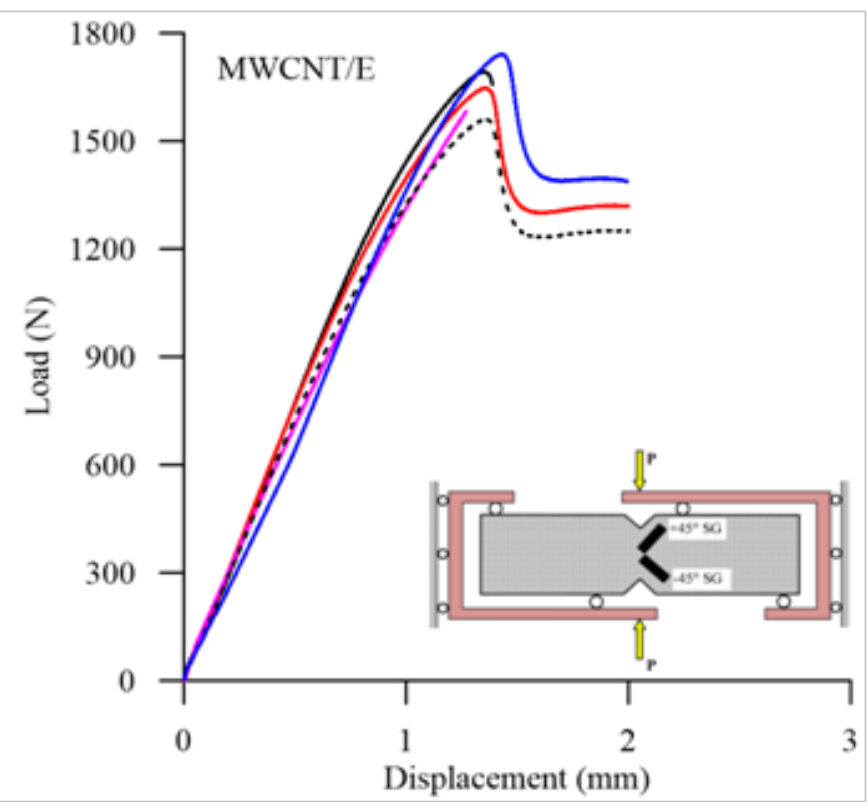

(b)

Fig. 13: Load-displacement curves of: (a) neat epoxy, and (b)MWCNT-nanocomposite. 


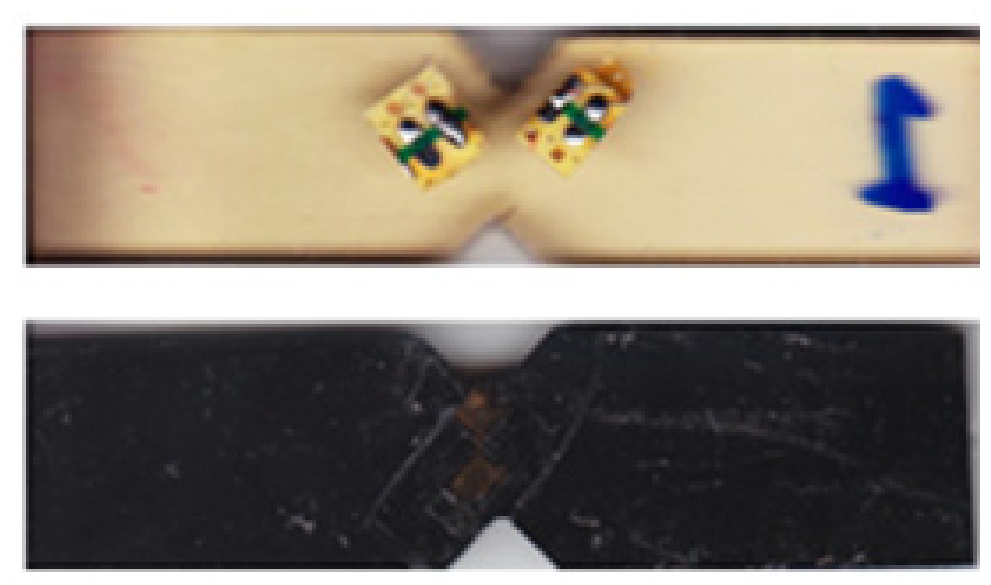

(a)

(b)

Fig. 14: Fractured specimens in shear test for : (a) NE, and (b) MWCNT-

The shear strengths of NE and MWCNT-nanocomposite were calculated by dividing the ultimate loads by the actual cross-section area of the test specimens (distance between the two $\mathrm{V}$-notches multiplied by thickness). The average values of the five tests are presented in bar chart as shown in Fig. 15. The results in this figure showed that the improvement percentage in the shear strength of the MWCNT-nanocomposite is $22.2 \%$ compared with NE.

The shear strains $\left(\gamma_{x y}\right)$ of neat epoxy and MWCNTnanocomposite were measured by strain gauges, which were bonded at ${ }^{0} 45$ at the center of the test specimen. Fig. $16 \mathrm{a}$ and $\mathrm{b}$ shows strains of $\pm 45^{\circ}$ SGs versus shear stress of neat epoxy and MWCNT-nanocomposite, respectively.

Fig. $17 \mathrm{a}$ and $\mathrm{b}$ shows shear stress-shear strain relationships of neat epoxy and MWCNT-nanocomposite, respectively. The in-plane shear moduli $\left(G_{x y}\right)$ of NE and MWCNT-nanocomposite were estimated from the slope of the initial linear region of shear stress vs shear strain curves of Fig. 17.

The average values shear modulus of the five tests are presented in bar chart as shown in Fig. 18. The results in this figure showed that the improvement percentage in the shear modulus of the CNTs/E nanocomposite is $29 \%$ compared with neat epoxy (NE). The improvement of the shear properties (strength and modulus) of MWCNTnanocomposite was attributed to the bridging effect of the MWCNTs, which arresting or retarding crack propagation between the two V-notches of the test specimen.

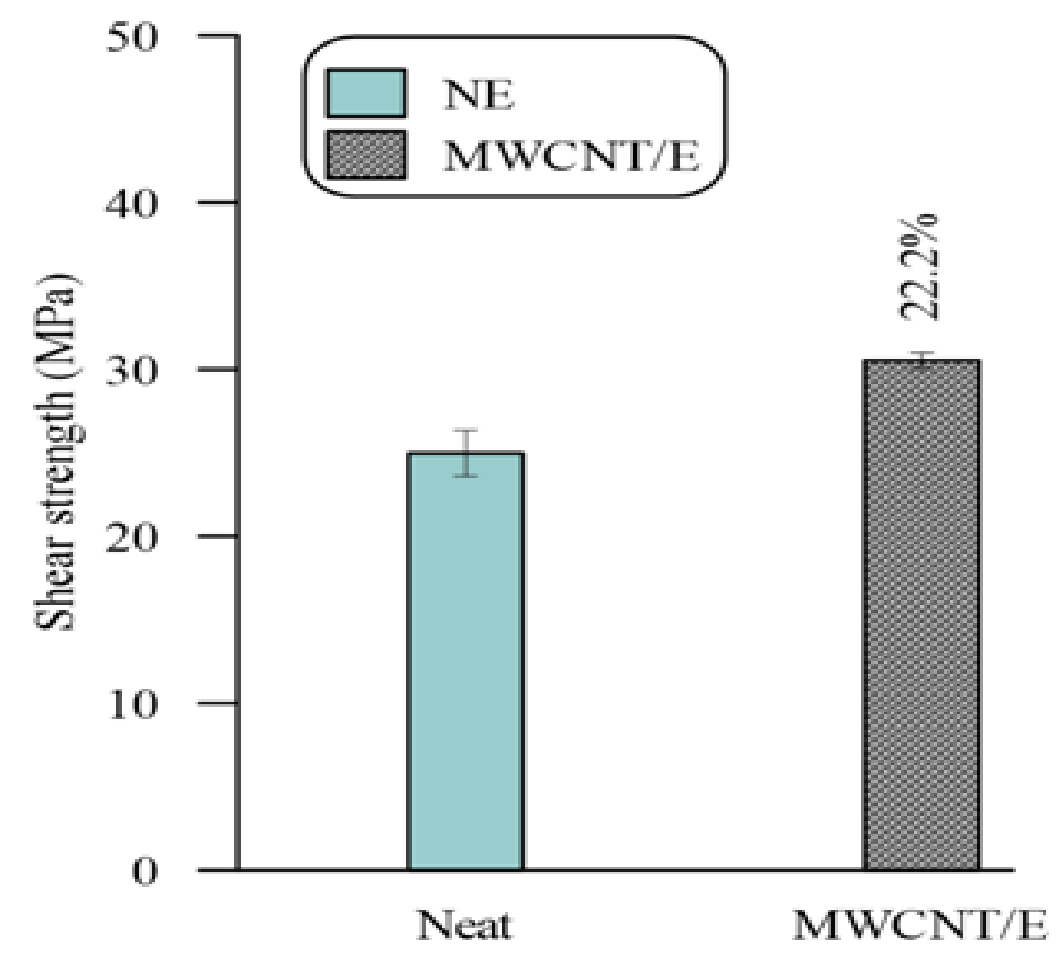

Fig. 15: Shear strength of NE and MWCNT-nanocomposite and the improvement percentage. 

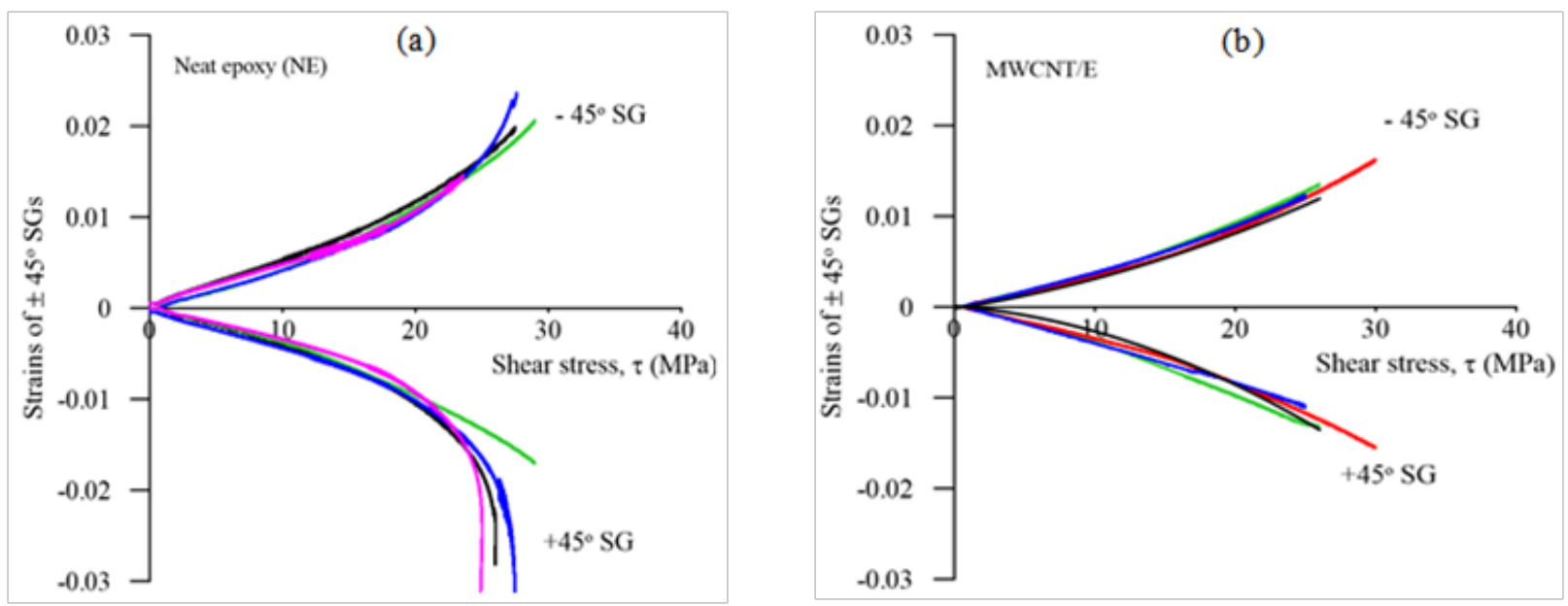

Fig. 16: Strains of $\pm 45^{\circ}$ SGs versus shear stress of: (a) NE, and (b) MWCNT-nanocomposite nanocomposite.
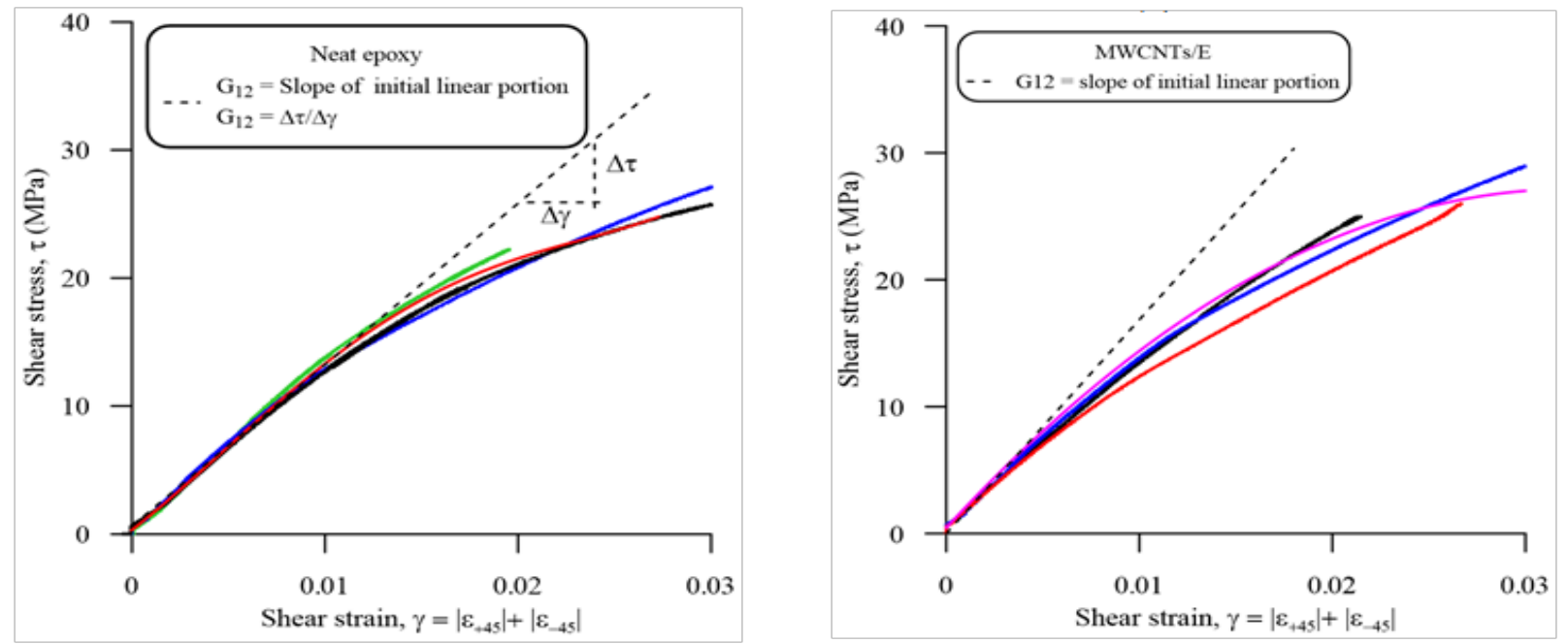

Fig. 17: Shear stress-shear strain relationship of: (a) NE, and (b) MWCNT-nanocomposite.

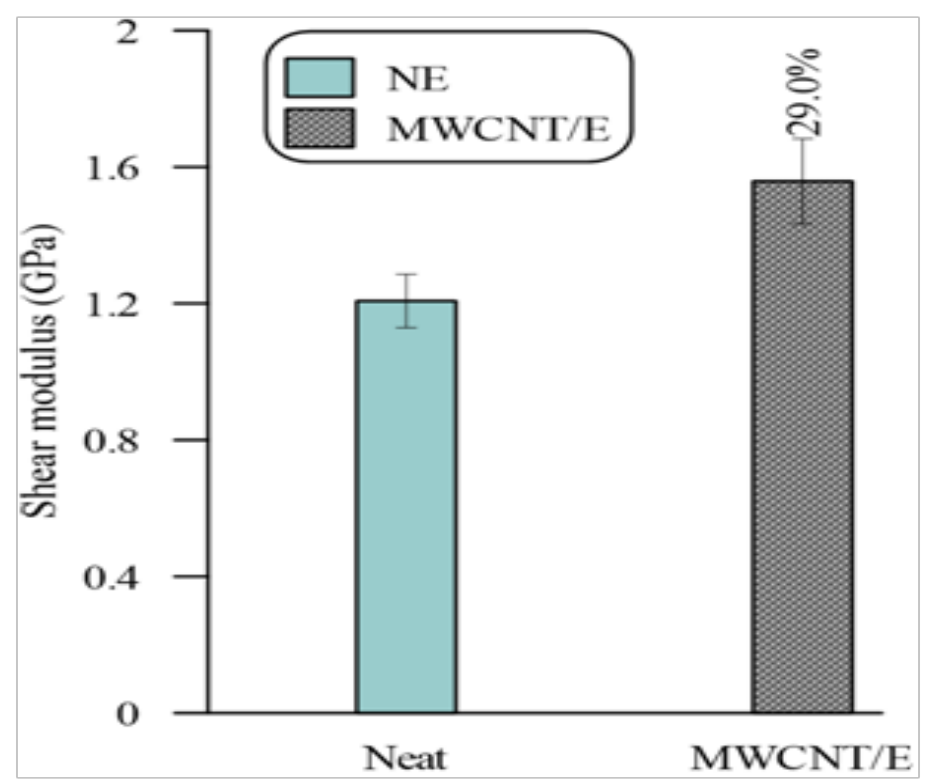

Fig. 18: Shear modulus of NE and MWCNT-nanocomposites and the improvement percentage. 


\subsection{Impact Test Results}

Fig. 19 shows contact force vs displacement and energy vs displacement relationships of NE and MWCNTnanocompositein drop-weight impact tests under impact energy of 20J. The first stage of force vs. impactor displacement (specimen deflection) curves of the NE and MWCNT-nanocomposite showed that the force was linearly increased, as the specimen deflection increases, up to a critical threshold force $F_{\text {threshold }}$ that is related to damage initiation ${ }^{[26]}$. The initial linear region of the forcedisplacement curves of Fig. 19 was due to the elastic bending of the specimens. The bending elastic stiffness can be calculated from the slope of the initial linear portion of the force-displacement curves of Fig. 19. The results in Fig. 19 showed that the MWCNT-nanocomposite has higher stiffness compared with NE. This result agrees well with the increase of the tensile and shear moduli of the MWCNTnanocomposite relative to NE as shown in Figs. 12 and 18, respectively. The drop in the force-displacement curves after the initial damage (at $\mathrm{F}_{\text {threshold }}$ ) is followed by further increases in the force up to the maximum force $\left(\mathrm{F}_{\text {peak }}\right)$ with slope lower than the initial linear portion. The peak force is followed by a sudden drop due to the catastrophic fracture of the specimen accompanied with impactor perforation/ penetration of the specimen.

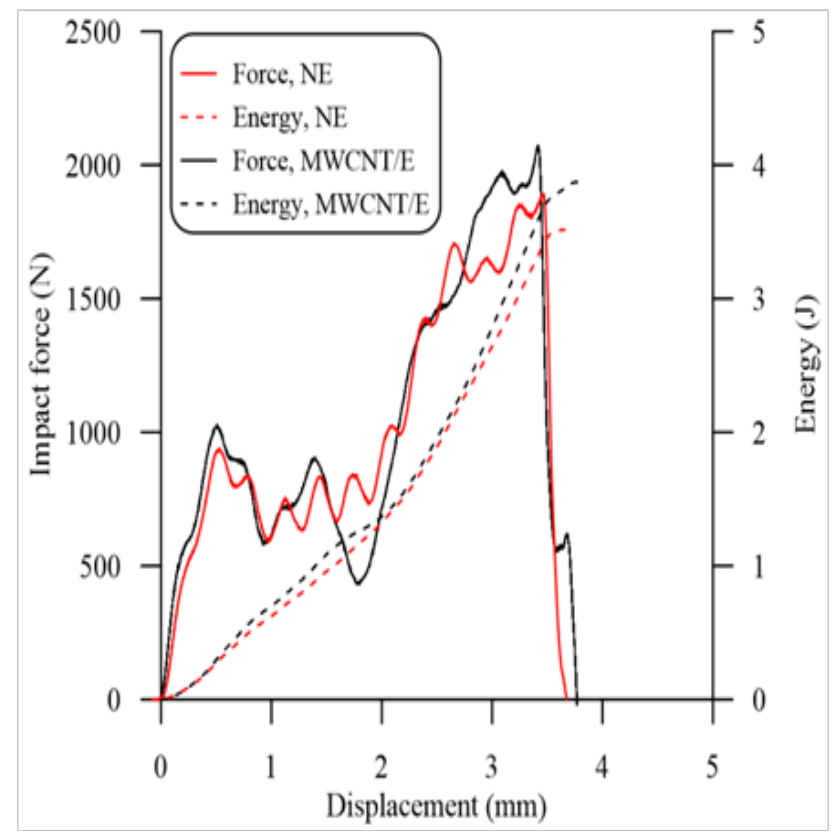

Fig. 19: Force and energy versus displacement in impact tests of NE and MWCNT-E nanocomposite.

Figs. 20 and 21 show the average values of the maximum contact force and energy at failure of NE and MWCNT-nanocomposite, respectively. The results in Figs. 20 and 21 showed that incorporation of MWCNTs into the epoxy improve the maximum contact force and energy at failure of the MWCNT-nanocomposite by $9.5 \%$ and $11.4 \%$, respectively. These improvements are in the range of the improvement in the tensile strength of MWCNT-nanocomposite(11\%). The improvement in the maximum contact force of the MWCNT-nanocomposite was attributed to the improvement in the tensile strength, whereas the improvement in the absorbed energy was due to the energy consumed in pull-out the MWCNTs.

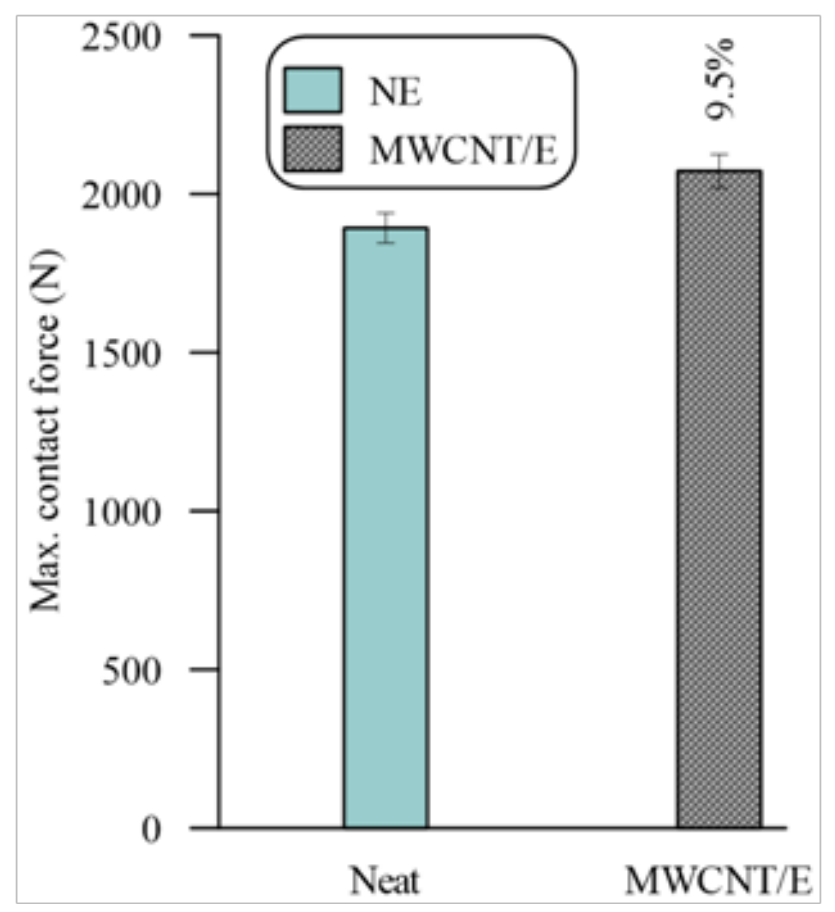

Fig. 20: Max. contact force of NE and MWCNT-nanocomposites and the improvement percentage.

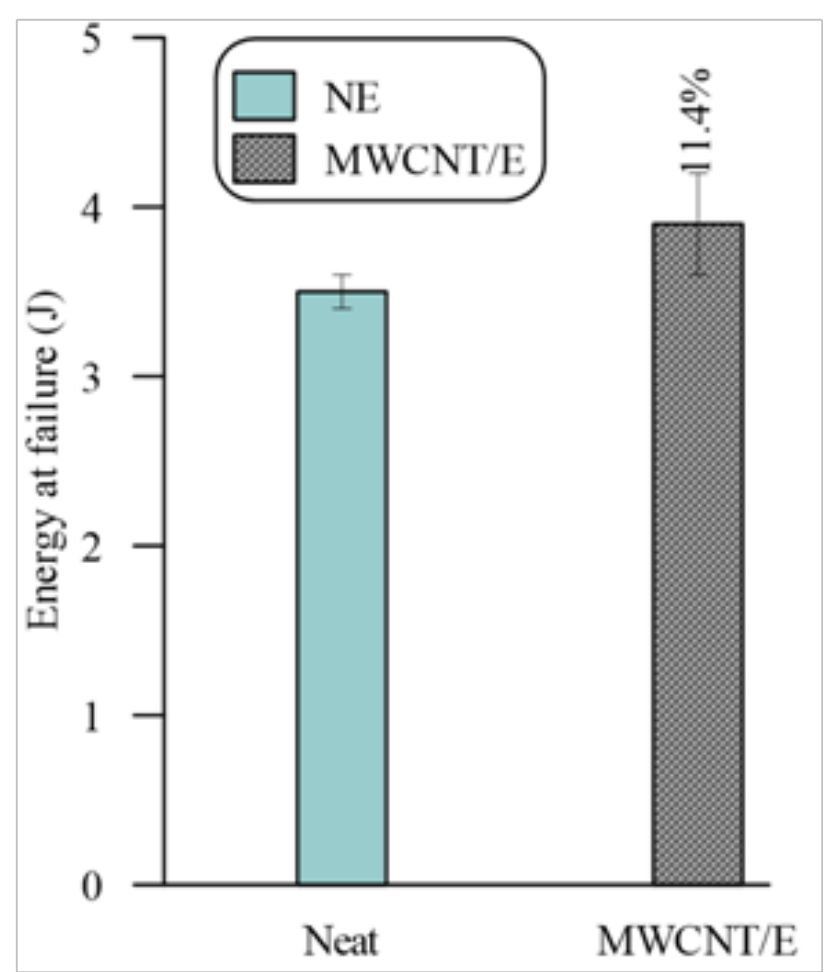

Fig. 21: Energy at failure of NE and MWCNT-nanocomposites and the improvement percentage. 


\section{CONCLUSIONS}

In this work, the effects of MWCNTs infusion into epoxy resin on the tensile, shear and impact properties were measured experimentally in accordance with ASTM standards. Experimental results of the modified epoxy with MWCNTs are compared with the neat epoxy (NE). Some of the important concluding remarks are summarized as follows:

- The fractures of the tensile test specimens are in the gauge lengths (away from the grips of the testing machine), which satisfy the condition of the ASTM D 638. The well dispersed MWCNTs in epoxy resin act as physical crosslinks for the epoxy molecular chains and accordingly, the tensile strength and modulus of the nanocomposite were improved by $11 \%$ and $68.7 \%$, respectively, compared to the neat epoxy.

- Incorporation of the MWCNTs into the epoxy resin improved the shear strength and modulus of the MWCNTnanocomposite by $22.2 \%$ and $29 \%$, respectively, compared with the neat epoxy. The improvement of the shear properties (strength and modulus) of MWCNTnanocomposite was attributed to the bridging effect of the MWCNTs, which arresting or retarding crack propagation between the two V-notches of the test specimen.

- The force vs. specimen deflection (impactor displacement) relationships of the drop weight impact of the MWCNT-nanocomposite showed higher bending elastic stiffness compared with NE. This result agrees well with the increase of the tensile and shear moduli of the MWCNT-nanocomposite relative to NE. The improvement percentages in the maximum contact force and absorbed energy of the MWCNT-nanocomposite are $9.5 \%$ and $11.4 \%$, respectively. The improvement in the maximum contact force of the MWCNT-nanocomposite was attributed to the improvement in the tensile strength $(11 \%)$, whereas the improvement in the absorbed energy was due to the energy consumed in pull-out the MWCNTs from the epoxy matrix.

\section{REFERENCES}

[1] Wang Z-J, Kwon D-J, Gu G-Y, Kim H-S, Kim D-S, X Lee G-Y, DeVries KL, Park J-M. Mechanical and interfacial evaluation of CNT/polypropylene composites and monitoring of damage using electrical resistance measurements. Composites Science and Technology (2013); 81: 69-75.

[2] Jen Y-M, Wang Y-C. Stress concentration effect on the fatigue properties of carbon nanotube/epoxy composites. Composites: Part B 43 (2012) 1687-1694.

[3] Mactabi R, Rosca ID, Hoa SV. Monitoring the integrity of adhesive joints during fatigue loading using carbon nanotubes. Composites Science and Technology 78 (2013) 1-9.

[4] Gojny FH, Wichmann MHG, Fiedler B, Schulte K. Influence of different carbon nanotubes on the mechanical properties of epoxy matrix composites - A comparative study. Composites Science and Technology
65 (2005) 2300-2313.

[5] Montazeri A, Chitsazzadeh M. Effect of sonication parameters on the mechanical properties of multi-walled carbon nanotube/epoxy composites. Materials and Design 56 (2014) 500-508.

[6] Yang J-P, Chen Z-K, Feng Q-P, Deng Y-H, Liu Y, Ni Q-Q, Fu $\mathrm{S}-\mathrm{Y}$. Cryogenic mechanical behaviors of carbon nanotube reinforced composites based on modified epoxy by poly(ethersulfone). Composites: Part B 43 (2012) 22-26.

[7] Khashaba UA, Aljinaidi AA, Hamed MA. Nanofillers modification of Epocast 50-A1/946 epoxy for bonded joints. Chinese Journal of Aeronautics 27(2014)1288-1300.

[8] Khashaba UA, Aljinaidi AA, Hamed MA. Analysis of adhesively bonded CFRE composite scarf joints modified with MWCNTs. Composites: Part A 71 (2015) 59-71.

[9] Khashaba UA, Aljinaidi AA, Hamed MA.Fatigue and reliability analysis of nano-modified scarf adhesive joints in carbon fiber composites. Composites Part B 120 (2017) 103-117.

[10] Khashaba UA, Najjar IMR. Adhesive layer analysis for scarf bonded joint in CFRE composites modified with MWCNTs under tensile and fatigue loads. Composite Structures 184 (2018) 411-427.

[11] Khashaba UA. Analysis of bolted/bonded joints modified with MWCNTs in CFRE composites under different temperature environments. Accepted, Composite Structures (2018)

[12] Hu L, Hecht DS, Grüner G. Carbon nanotube thin films: fabrication, properties, and applications. Chem Rev 2010;110(10):5790-844.

[13] Cheng Q, Debnath S, Gregan E, Byrne HJ. Ultrasound-assisted SWNTs dispersion: effects of sonication parameters and solvent properties. J PhysChem C. 2010;114(19):8821-7.

[14] Steinmetz J, Glerup M, Paillet M, Bernier P, Holzinger M. Production of pure nanotube fibers using a modified wet-spinning method. Carbon 2005;43(11):2397-429.

[15] Tao K, Yang S, Grunlan JC, Kim Y-S, Dang B, Deng Y, Thomas RL, Wilson BL, Wei X. Effects of carbon nanotube fillers on the curing processes of epoxy resin-based composites. J. ApplPolymSci (2006);102(6):5248-5254.

[16] Sawi IE, Olivier PA, Demont P, Bougherara H. Investigation of the effect of double-walled carbon nanotubes on the curing reaction kinetics and shear flow of an epoxy resin. J ApplPolymSci

(2012); 126(1): 358-366

[17] Korayem AH, Li CY, Zhang QH, Zhao XL, Duan WH. Effect of carbon nanotube modified epoxy adhesive on CFRP-to-steel interface. Compos Part B-Eng (2015);79: 95-104

[18] Bal S. Experimental study of mechanical and electrical properties of carbon nanofiber/epoxy composites. Mater Design (2010); 31: 2406-2413.

[19] Khashaba UA. Improvement of toughness and shear properties of multi-walled carbon nanotubes/epoxy composites. Polymer composites 39(2018) 815-825.

[20] Uddin MF, Sun CT, Improved dispersion and mechanical properties of hybrid nanocomposites. Compos SciTechnol (2010);70: 223-230.

[21] Taurozzi JS, Hackley VA, Wiesner MR. Protocol for the preparation of nanoparticle dispersions from powdered material using ultrasonic disruption. Ceint/Nist Protocol (http://ceint.duke.edu/allprotocols), Ver.1, (2010).

[22] Bittmann B, Haupert F, Schlarb AK. Ultrasonic dispersion of inorganic nanoparticles in epoxy resin. UltrasonSonochem (2009); 16: 622-628.

[23] Tech Tip 4, www.epotek.com, Removing Bubbles from Epoxy" Epoxy Technology Inc. 14 Fortune Drive, Billerica, MA 01821.

[24] Bhatanagar N, Ramakrishnan N, Naik NK, Komanduri R. On the machining of fiber reinforced plastic (FRP) composite laminates. J Mach Tools Manufact(1995); 35(5): 701-16.

[25] Khashaba UA. In-plane shear properties of cross-ply composite laminates with different off-axis angles. Composite Structures 65 (2004) $167-177$.

[26] Khashaba UA, Othman R. Low-velocity impact of woven CFRE composites under different temperature levels. International Journal of Impact Engineering 108(2017)191-204. 